\title{
Elektrik ark ocağı ile üretim yapan bir demir-çelik tesisinin mevcut en iyi teknikler kapsamında değerlendirilmesi
}

\section{Evaluation of an iron and steel mill producing by electric arc furnace in the scope of best available technics}

\author{
Gülizar Gökcecik 1(D), Hakan Dulkadiroğlu2,* \\ 1,2 Nevşehir Hacı Bektaş Veli Üniversitesi, Çevre Mühendisliği Bölümü, 50300, Nevşehir, Türkiye
}

\begin{abstract}
Özet
Ülkemizin gelişen ve üreten sektörü olan demir-çelik sanayii, meydana getirdiği atık miktarı ile de büyük bir öneme sahiptir. Cevher ve hurda metalden üretim gerçekleştiren demir-çelik sektörü, hammadde türüne göre entegre ve elektrik ark ocaklı demir-çelik tesisi olarak ikiye ayrılmaktadır. Demir-çelik tesislerinden kaynaklanan katı atıkların birçok alanda geri dönüşümü sağlanabilmekte ve ekonomiye katkı sağlamaktadır. Bu çalışma kapsamında, elektrik ark ocağı ile üretim yapan bir demir-çelik tesisinin Mevcut En İyi Teknikler (MET) kapsamında değerlendirilmesi amaçlanmıştır. Ülkemizdeki elektrik ark ocaklı tesislerden biri olan Baştuğ Metalurji San. A.Ş. demir-çelik tesisinin çelikhane ünitesi MET kapsamında incelenmiştir. İşletmenin çelikhane bölümünde yapılan incelemelerde mevcut durumun, MET Referans Dokümanı (BREF) ile büyük oranda uyumlu olduğu ve Entegre Kirlilik Önleme ve Kontrol Direktifi'nin gereklerini karşıladığı tespit edilmiştir.
\end{abstract}

Anahtar kelimeler: Demir-çelik, Mevcut en iyi teknikler, Geri dönüşüm, Yeniden kullanım, Endüstriyel atık

\section{Giriş}

Demir-çelik üretimi sırasında bir ton çelik başına 400 kg'1 aşan miktarlarda katı atık oluşur [1]. Oluşan bu katı atıkların gelişigüzel çevreye atılması veya tesislerin boş sahalarında biriktirilmesi, içerdikleri toksik etkili ağır metaller ve bileşiklerin yağmur ve kar suları ile yeraltı sularına geçmesine neden olabilmektedir. Bununla birlikte toprağa karışarak hem bitki örtüsünü hem de hayvan ve insan sağlığını önemli ölçüde tehdit etmektedir. Oluşan katı atıkların bertaraf edilmesi durumunda ise ağır ekonomik yük oluşmaktadır. Demir-çelik tesislerinde oluşan yan ürünlerin geri kazanımı ve yeniden kullanımı Dünya Çelik Örgütü tarafından sıfır atı̆̆a ulaşmanın en iyi yolu olarak değerlendirilmiştir.

Sanayinin pek çok dalıyla ilişkili olan demir-çelik sektörü; en başta inşaat sektörü olmak üzere her türlü makine-ekipman imalatı, otomotiv sanayii, motorlu taşıtlar sanayii vb. için girdi sağlamaktadır. Sektörün ana hammaddesi cevher ve hurda olup, temel çıktısı ise ham

\begin{abstract}
Iron and steel industry, which is the developing and producing sector of our country, has a great importance with the amount of waste it generates. The iron and steel industry, which produces from ore and scrap metal, is divided into two type depending on the raw material as integrated and electric arc furnace. Solid wastes from iron and steel plants can be recycled in many areas and contribute to the economy. Within the scope of this study, it is aimed to evaluate of an iron and steel mill producing by electric arc furnace in the scope of Best Available Technics (BAT). The steelwork unit of Baştuğ Metallurgy Co. Inc. iron and steel plant, which is one of the electric arc furnace facilities in Turkey, has been examined within the scope of the BAT. According to the results of investigation carried out in the steel plant, it was determined that the current situation is highly compatible with BREF (BAT Reference Document) and the plant meets the requirements of IPPC (Integrated Pollution Prevention and Control) Directive.
\end{abstract}

Keywords: Iron-steel, Best available technics, Recycling, Reuse, Industrial waste

çeliktir. Uzun (kütük) ve yassı (slab) yarı mamuller ham çelikten üretilen son ürünlerdir. Haddeleme işleminden sonra yass1 yarı mamullerden rulo sac ile birlikte sac levha üretimi gerçekleşmektedir. Yine haddeleme süreci sonunda uzun yarı mamuller inşaat demiri, filmaşin, kangal, dikişsiz boru, profil, ray, lama gibi ürünler elde edilmektedir. Galvanizleme ve boya işlemleri tüketici isteğine göre gerçekleştirilmektedir.

Ülkemizde sürekli gelişim gösteren demir-çelik sektörü üretim kapasitesini gün geçtikçe yükseltmektedir. Demirçelik tüketimi ülkemizde kişi başına $415 \mathrm{~kg}$ civarında iken, gelişmiş ülkelerde bu miktar 400-500 kg aralığındadır. 1983 yılında Türkiye ham çelik üretiminde 3.8 milyon ton ve $\% 0.57^{\prime}$ lik pay ile dünyada 28 . ülke konumundayken, 2011 yılında 34.1 milyon tona ulaşarak ilk 10 arasına girmeyi başarmıştır. 2013 yılında ise ham çelik üretim miktarını 34.7 milyon tona yükselerek dünya piyasasında ortalama \%2.1'lik paya sahip olmuştur. Türkiye, günümüzde dünyada çelik

\footnotetext{
* Sorumlu yazar / Corresponding author, e-posta / e-mail: hakandulkadiroglu@ @nevsehir.edu.tr (H. Dulkadiroğlu)

Geliş / Recieved: 11.11.2020 Kabul / Accepted: 12.02.2021 Yayımlanma / Published27.07.2021

doi: 10.28948/ngumuh.824701
} 
üretimi yapan 65 ülke arasında 8. sırada, Avrupa'da ise 2. sirada yer almaktır [2-4].

Demir-çelik üretimi sırasında oluşan katı atıkların içerisinde cüruf \%70-80'lik bir oranla en yüksek paya sahiptir [1]. Diğer oluşan katı atık türleri ise yüksek firın toz ve çamurları, sinter fabrikalarının tozları, çelikhane toz ve çamurları, pota metalurji tesisleri tozları, yağlı tufaller, haddehane tufalleri ve ark ocağı tozlarıdır. Genel anlamda bu atıklar tozlar, çamurlar ve tufaller biçiminde 3 ana başlık altında toplanır (Şekil 1) [5].

Demir-çelik tesislerinde oluşan katı atıkların büyük bir kısmını oluşturan cürufların dişında kalan, içerisinde demir ve karbon bulunduran ve değerli atık olarak nitelendirilen atıkların en önemlileri şunlardır [6]:

1. Yüksek firın toz ve çamurları

2. Sinter tozları

3. Çelikhane toz ve çamurları

4. Pota metalurji tesisleri tozları

5. Yağlı tufaller

6. Haddehane tufalleri

7. Ark ocağı tozları

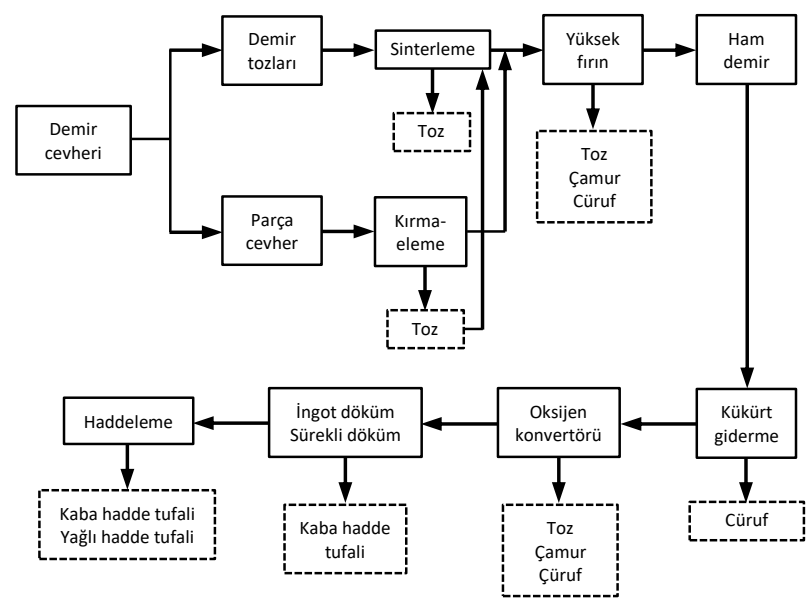

Şekil 1. Entegre demir-çelik tesislerinden ortaya çıkan atık türleri [7]

Yan ürün atık oksitler; tozlar, cüruflar, çamurlar ve yağ $1_{1}$ yağsız tufaller olarak gruplara ayrılır. Ortaya çıkan toz, çamur ve tufaller ekonomik değeri olan atıklardır. Demir oksit ve karbon gibi önemli bileşikleri ihtiva ederler. Çoğunlukla bu atıkların geri dönüşümü, elek analizi ve kimyasal analizi yapıldıktan sonra sinter ünitesinden geçirilerek yüksek fırınlarda sağlanır. Yan ürün oksitlerin geri dönüşümünün birtakım dezavantajları vardır [8,9].

Cüruf: Çevresel ve ekonomik getiri sağlayan cürufun geri dönüşümü tesise enerji tasarrufu sağlarken, bertaraf maliyetini ve atığ 1 azaltmaya yardımcı olmaktadır. Ayrıca tesislerdeki fırınların ömrünü uzatarak sektöre büyük kazançlar sağlamaktadır [10]. Atık cürufların geri kazanım alternatiflerinden biri yol yapımında kullanım olup; malzeme içerisinde bulunan organik ve inorganik tehlikeli maddelerin yağmur ve kar sularıyla içme suyu ve yeraltı sularına sızması durumu bu uygulamada dikkat edilmesi gereken önemli bir noktadır. Yeraltı sularına karışması durumunda, oluşan kirleticiler çevre için büyük sorunlara neden olabilmektedir [11]. Oluşan cürufların diğer değerlendirme alternatifleri 4 şekilde olabilmektedir [12];

1. Demir-çelik sektörü için sentetik cüruf yapıcı (alüminyum esaslı flaks) olarak kullanılması,

2. Alüminyum endüstrisi için tuz flaksları olarak kullanılması,

3. İkincil alümina üretiminde kullanılması,

4. Çimento endüstrisi için katkı malzemesi olarak kullanılması.

Yüksek Fırın Baca Tozları ve Çamurları: Demir-çelik üretiminde oluşan toz atıkların içeriğinde yüksek miktarda demir oksit bulunduğundan değerli hammadde özelliği taşımaktadırlar ve çevre mevzuatının katı ve tehlikeli atıklar için getirdiği kısıtlamalardan dolayı bu toz atıkların sahada imha edilmesi oldukça maliyetlidir. $\mathrm{Bu}$ durumdan dolayı oluşan toz ve diğer atıkların geri kazanımı zorunlu bir hal almaktadır. Toz atıkların geri kazanımı sırasında sinterleme adı verilen özel bir işleme tabi tutulması gerekmektedir [13].

Sinter Tozları: 19. yüzyılda metal endüstrisinde kesikli bir işlem olarak ortaya çıkan sinterleme, demir cevherlerinin yanı sıra bakır ve kurşun cevherleri içinde kullanılmıştır. Sinterleme toz cevherlerin aglomerasyon yolu ile yüksek fırın için istenen parça büyüklüğüne, mukavemete ve gaz geçirgenliğine sahip duruma getirilmesi işlemidir. İşlem sonucunda büyük ve gözenekli parçalar elde edilir. Sinterleme, pudra yapısındaki partiküllerin atomlarının, 1S1 etkisi ile oluşan kısmi ergime sonucu ufak parçaların temas yüzeylerinden birbirine yapışmaları, yeniden kristalleşme ile difüzyon bağlarının oluşması ve parçaların birbirine yapışmalarını sağlayan hematit ve manyetit kristallerinin büyümesi işlemi olarak da tanımlanabilir. $\mathrm{Bu}$ işlemler toz cevherlerle karıştırılmış olan kok tozunun yanması sırasında meydana gelmekte ve sabit veya hareketli sinter makineleriyle yapılmaktadır [14].

Tufal: Demir-çelik tesislerinde üretim sonucunda meydana gelen yarı ürün niteliğindeki çeliğin kütük halini alması için sıcak halde haddelenerek şekil alması sağlanır. $\mathrm{Bu}$ süreç sonucunda, yüksek sıcaklık etkisiyle çelik yüzeyinde oksitlenme meydana gelerek ince bir demir oksit tabakası oluşur. Bu tabakaya tufal adı verilmektedir [5]. Tufaller yüksek oranda demir içerdiklerinden ve aynı zamanda zararlı safsızlıklar içermediklerinden, entegre demir-çelik tesislerindeki sinter fabrikasında kullanılabilmektedir ve hatta dişarıdan satın alınmaktadır $[15,16]$. Tehlikeli atıklar içerisinde en büyük hacme sahip olan, sürekli döküm ve sıcak haddehanelerin su devridaim tesislerinden açığa çıkan yağlı tufal ise sinter tesisinde kullanılamamaktadır [17].

Avrupa Konseyi tarafından ilk olarak 24 Eylül 1996 tarihinde kabul edilen 96/61/EC kodlu "Integrated Pollution Prevention and Control" (IPPC), yani Entegre Kirlilik Önleme ve Kontrol (EKÖK) direktifi "çevrenin bir bütün olarak üst seviyede korunmasını sağlamak amacıyla, atıkları da içeren tedbirler dahil olmak üzere, yüksek kirletici potansiyeline sahip sanayi ve tarım faaliyetlerinden kaynaklanan emisyonların önlenmesi için, bunun mümkün olmadığı durumlarda da havadaki, sudaki ve topraktaki emisyonların azaltımı için tasarlanmış tedbirleri ortaya 
koyar”. Direktif, 15 Ocak 2008 yılında 2008/1/EC koduyla revize edilmiş ve son olarak da 24 Kasım 2010 tarihinde 2010/75/EU kodlu ve "Industrial Emissions" (Endüstriyel Emisyonlar) başlıklı son hali kabul edilmiştir. Demir-çelik sektörü, Entegre Kirlilik Önleme ve Kontrol Yönetmeliği Ek-1'de "Madde 1.3: Kok firınları" ve "Madde 2: Metallerin üretilmesi ve işlenmesi" ile atıfta bulunulan endüstriyel faaliyet kategorileri arasına dahil edilmiştir [18, 19].

$\mathrm{Bu}$ çalışmada Mevcut En İyi Teknikler (MET) rehber dokümanlarının uygulamadaki karşılığının ne ölçüde gerçekleştiğinin ortaya konması amaçlanmıștır. $\mathrm{Bu}$ kapsamda, seçilen bir elektrik ark ocaklı (EAO) demir-çelik işletmesindeki MET uygulamaları incelenmiş ve MET Referans Dokümanı (BREF) ile karşılaştırılarak kirlilik önleme ve geri kazanıma yönelik olarak tesisin mevcut durumu değerlendirilmiștir.

\section{Materyal ve metot}

\subsection{Materyal}

Çalışma kapsamında Osmaniye Organize Sanayi Bölgesi'nde faaliyet gösteren Baştuğ Metalurji A.Ş.'ye ait demir-çelik işletmesi incelenmek üzere seçilmiş ve işletmenin çelikhane ünitesi MET kapsamında değerlendirilmiştir (Şekil 2). İşletme 145.000'i kapalı, toplam $700.000 \mathrm{~m}^{2}$ 'lik alanda faaliyet göstermektedir. Y1lda 2.000.000 ton sıvı çelik üretimi gerçekleștiren Baştuğ Metalurji'de, dünyada bir ilk olarak kullanılan teleskopik tip EAO günlük 6500 ton sıvı çelik üretim kapasitesine sahiptir. Son olarak yapılan entegre haddehane yatırımı ile Ø8-Ø65 mm arası nervürlü inșaat demiri üretim kapasitesine sahip olmakla birlikte, 2020 yılında $\varnothing 8-\varnothing 40 \mathrm{~mm}$ arası nervürlü inşaat demiri üretilmektedir [20]. İşletme toplamda 755 kişiyi istihdam etmektedir.

Baştuğ Metalurji tesisinde 1 adet çelikhane, 1 adet nervürlü inşaat demiri haddehanesi, 1 adet oksijen üretim tesisi, 1 adet su tesisi ve 1 adet şalt tesisi bulunmaktadır. Tesiste toplam 229 MWh elektrik enerjisi tüketilmektedir. Baştuğ Metalurji, gerekli olan elektrik enerjisini özel bir elektrik şirketinden sağlamaktadır, tesis bünyesinde bir elektrik üretim tesisi bulunmamaktadır.

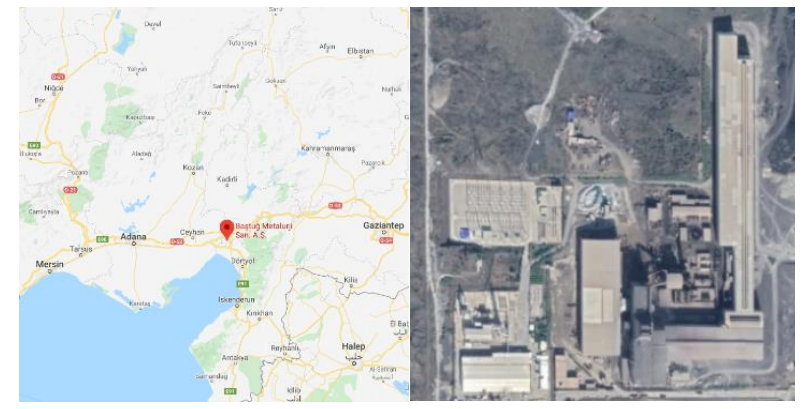

Şekil 2. Baştuğ Metalurji Demir-Çelik Tesisi'nin konumu ve uydu görüntüsü

Baştuğ Metalurji'nin iki ana ünite olarak üretim gerçekleştiren çelikhane ve haddehane tesislerinin 2014 yılı itibariyle toplam üretim kapasiteleri şu şekildedir:
- Çelikhane tesisi toplam üretim kapasitesi: 2.000.000 ton/yıl sıvı çelik

- Haddehane tesisi toplam üretim kapasitesi: 1.250 .000 ton/y1

\subsection{Metot}

Seçilen tesis Avrupa Komisyonu tarafindan yayımlanan Demir ve Çelik Üretimi için BREF [21] dokümanında yer verilen öneriler kapsamında incelenmiş ve yetkililerden gerekli veriler temin edilmiştir. Elde edilen bilgiler ışı̆̆ında kirlilik önleme ve geri kazanıma yönelik olarak tesisin mevcut durumu değerlendirilmiştir.

\section{Bulgular ve tartışma}

Avrupa Komisyonu tarafindan yayımlanan Demir ve Çelik Üretimi için MET Referans Dokümanı (BREF) [21] esas alınarak işletmede yapılan incelemeler sonucunda elde edilen bulgular aşağıda açıklanmıștır.

\subsection{Hammadde depolama ve kontrol}

Hammadde olarak kullanılacak olan hurdalar işletmede bulunan kapasitesi yaklaşı $300.000 \mathrm{t}$, hacmi $610.000 \mathrm{~m}^{3}$ olan 8 adet kapalı holde depolanmaktadır. Bölümlere ayrılmış haldeki hollerde farklı çeşitteki hurdaları birbirine karıştırmadan stoklanabilmektedir. Farklı kalitedeki hurdalar 4 adet tavan vinci ile hurda sepetlerine aktarılmaktadır. Hurdanın gemiden tahliyesi, fabrika sahasına girişi, üretime çıkışı ve stok yerleri otomasyon sistemi ile kontrol ve takip edilmektedir. Tesis girişindeki hammadde ana giriş kantarında radyasyon ölçümü yapılarak tehlikeli maddelerin girişi önlenmektedir. Kurşun, bakır gibi metaller hammadde içerisinden ayıklanarak hurda bekleme sahasına koyulmaktadır. Hurda kalitesi kontrol mühendisleri tarafından incelenmektedir. $\mathrm{Bu}$ önlemlerin haricinde, hurdanın temin edildiği yer hakkında çeşitli incelemeler yapılıp, buna göre gerekli tedbirler uygulanmaktadır. İşletmedeki depolama ve hurda ayrımı faaliyetleri BREF ile uyumlu olarak yürütülmektedir. Her ne kadar demir-çelik üretiminde radyoaktivite denetiminin öneminden BREF'te bahsedilmiş olsa da MET içeriğinde bir uygulama önerilmemiştir. Bununla birlikte, gelen hurda içeriğinde bulunabilecek radyoaktif maddelerin üretim aşamasına dâhil edilmemesi için işletmede önemli tedbirler uygulanmaktadır.

\subsection{Hurda ön ısıtma}

Tesiste hurda ön 1sıtma sistemi kullanılmaktadır. 2020 yılına ait proses bazında enerji sarfiyatları Tablo 1'de verilmiştir. Hurda ön 1sıtma ile sağlanan enerji tasarrufu ölçülememekle birlikte, y1llık yaklaşık 60.000.000 kWh olarak tahmin edilmektedir.

Tablo 1. İşletmenin 2020 y1lına ait proses bazındaki yıllık enerji tüketim değerleri

\begin{tabular}{lc}
\hline Proses & Enerji Sarfiyatı $(\mathrm{kWh})$ \\
\hline Ark ocağı & 689.475 .900 \\
Pota ocağ 1 & 51.281 .500 \\
Çelikhane & 60.594 .453 \\
Toz toplama & 22.379 .978 \\
Atölye & 352.054 \\
Haddehane & 55.193 .652 \\
Oksijen fabrikası & 48.037 .990 \\
Toplam & 927.315 .527 \\
\hline
\end{tabular}




\subsection{Elektrikli ark ocağı optimizasyonu}

Minimum enerji tüketimi ile üretimi maksimize etmeyi hedefleyen EAO proses optimizasyonu kapsamında; aşağıda belirtilen ve BREF [21] içeriğinde bulunan teknikler tesiste eksiksiz uygulanmaktadır:

- $\quad$ (Ultra) Yüksek güç uygulaması (UHP)

- Su soğutmalı yan duvarlar ve çatılar

- Oksi-yakıt yakıcılar ve oksijen verme

- Aşağidan dökme sistemi

- Köpüklü cüruf uygulamas

- $\quad$ Pota veya ikincil metalurji

- Otomasyon sistemleri

$170 \mathrm{t}$ kapasiteye sahip alternatif akım (AC) ve teleskopik tipli EAO, $1590^{\circ} \mathrm{C}$ sicaklıkta işletilmektedir. Dünya genelinde nadir kullanımı olan teleskopik tipli EAO’nun en önemli avantajı bir defa şarj edilmesidir.

Şarj sırasında firına kömür ve kireç ilavesi yapılmaktadır ve bunun sonucunda hurdanın eriyik maddesi oluşmaktadır. Dökümden döküme gerçekleşen seferleri minimize etmek için $165 \mathrm{MW}$ güce sahip firın transformerleri ile UHP verilmektedir. Proseste dökümden döküme geçen zaman ortalama $45 \mathrm{dk}$ 'dır. Ark ocağı yatay kolon su soğutmalı ve kapalı devredir. Geri kalan sistemlerin soğutması açık devredir. Enerji miktarını minimize etmek, refrakter ömrünü maksimize etmek ve 1sı kaybını en düşük seviyeye çekmek için "kapalı devre su soğutma sistemi" kullanılmaktadır. Eşanjörlerden geçen su öncelikle havuza, daha sonra soğutma kulesinden geçiş yaparak tekrar sisteme verilmektedir. Buharlaşma kaybı ham su ile tamamlanmaktadır. EAO'ya brülörler ile oksijen enjekte edilmekte ve bu sayede enerji tüketimi azaltılmaktadır.

EAO'larda cüruf-metal arasına oksijen ile ilave edilen karbonun cürufu köpürtmesi ve cüruf ile metalin birbirlerinden daha basit bir şekilde ayrılmasıyla oluşan sistem de tesiste mevcuttur. Ark ocağının alt bölümü aşağıdan dökme sistemi (EBT) olarak isimlendirilen holden oluşmakta ve bu hol vasıtasıyla da sıvı çelik potaya akmaktadır. Tüm bu bahsedilen sistemlerin takibi, merkezi kontrol denetim odasından kumanda edilen otomasyon sistemi ile verimli bir şekilde sağlanmaktadır.

\subsection{Ikincil metalurji}

Tesiste ikincil metalurji pota ocağında yapılmaktadır. Pota ocağına gelen sıvı çelik analize alınmakta, analiz sonucuna göre istenilen kaliteye gelmesi için gerekli ferro alyaj ilaveleri yapılmakta ve belli sıcaklığa getirildikten sonra döküm pota ocağından çıkartılmaktadır. Tesiste ham çelik ark ocağından potaya akarken, potaya silolardan mangan, silis ve kireç verilmektedir.

Tesiste MET kapsamında bulunan vakum uygulamasına ikame olarak çalkantı gerçekleştirmek ve isı dengesi sağlamak için çeliğe argon uygulanmaktadır.

\subsection{Kapalı devre su soğutma ve atıksu arıtma sistemleri}

İşletmeden kaynaklanan endüstriyel nitelikli atıksular soğutma sularından ibarettir, başka atıksu kaynaklanmamaktadır. Şekil 3'te görüldüğü gibi; kuyulardan çekilen suya, önce istenen özelliklerin sağlanması amacıyla kimyasal maddeler ilave edilerek şartlandırma yapılır, daha sonra kapalı devre su soğutma sistemine verilir. Soğutma sisteminde 1sı transferi titanyum kaplı eşanjörler yardımıyla sağlanmaktadır. Kapalı devre su soğutma sistemi MET ile uyumlu şekilde uygulanmaktadır.

\subsection{Ileri düzey emisyon toplama ve temizleme sistemleri}

İleri emisyon toplama sistemleri arasında baca veya tüm binada boşaltım için en uygun sistem 1 elektrot olduğu zaman 2. delik, 3 elektrot olduğu zaman ise 4. delik ile doğrudan çekmedir. İşletmede 3 elektrot bulunduğu için, birincil emisyonlar 4 . delik aracılığıyla toplanmaktadır. 4. delik sistemine ek olarak bütün işletmeyi kapsayacak bir baca sistemi de inşa edilmiştir. Bu uygulama BREF'te geçen ve Şekil 4'te gösterilen emisyon toplama sistemlerinden ilk sıradakine karşılık gelmektedir. Çelikhanede kullanılan yakıt türevlerinden ortaya çıkacak olan emisyon, duman emme sistemine geçmektedir. Prosesteki geçişler $650.000 \mathrm{Nm}^{3} / \mathrm{sa}$ kapasiteli 1 adet ana fan aracılığıyla emilerek sağlanmaktadır. Toplanan emisyon içerisindeki tozun $\% 5^{\prime} i$ dik siklonlarda, \%2'si soğutucularda ve \%93'ü filtrelemede tutulmaktadır. Tesiste oluşan emisyonların ortalama miktarları Tablo 2'de verilmiştir.

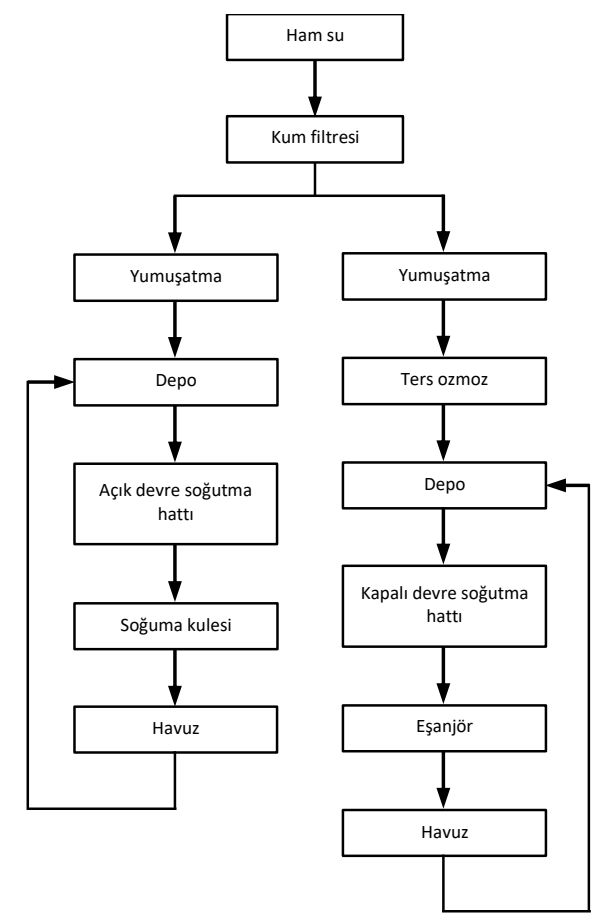

Şekil 3. Kapalı devre su soğutma sistemi

Tablo 2. Tesiste oluşan emisyonların ortalama miktarları

\begin{tabular}{ccccc}
\hline $\begin{array}{c}\text { Toz } \\
\left(\mathrm{mg} / \mathrm{Nm}^{3}\right)\end{array}$ & $\begin{array}{c}\mathrm{CO} \\
\left(\mathrm{mg} / \mathrm{Nm}^{3}\right)\end{array}$ & $\begin{array}{c}\mathrm{NO} \\
\left(\mathrm{mg} / \mathrm{Nm}^{3}\right)\end{array}$ & $\begin{array}{c}\mathrm{NO}_{2} \\
\left(\mathrm{mg} / \mathrm{Nm}^{3}\right)\end{array}$ & $\begin{array}{c}\mathrm{SO}_{2} \\
\left(\mathrm{mg} / \mathrm{Nm}^{3}\right)\end{array}$ \\
\hline 3,28 & 282 & 3,0 & 4,0 & 10 \\
\hline
\end{tabular}

\subsection{Etkin Sonradan Yakma}

Tesiste "etkin sonradan yakma" işlemi, ayrı bir yakma odasında gerçekleşmektedir. Bu işlem sayesinde atık gazdaki $\mathrm{CO}$ ve $\mathrm{H}_{2}$ 'in tam yanması sağlanarak, gaz temizleme sisteminde kontrolsüz reaksiyonlar oluşması önlenmektedir. 


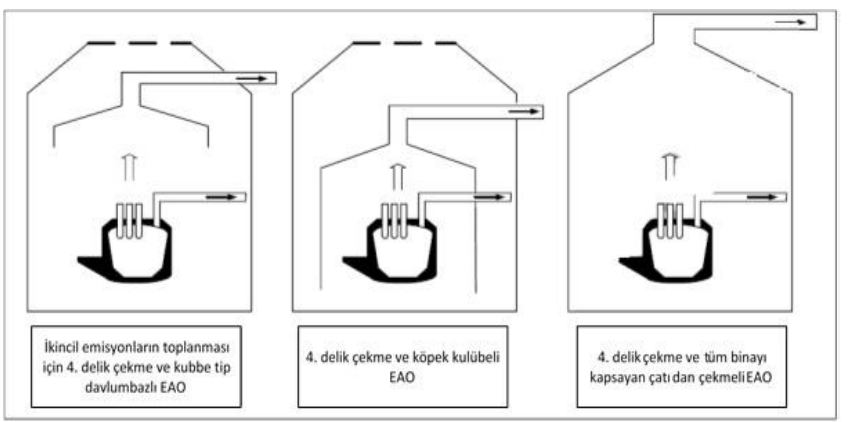

Şekil 4. EAO'larda kullanılan emisyon toplama sistemleri [19]

\subsection{Linyit kok tozu enjeksiyonu}

MET içeriğinde yer alan, atık gazların içeriğindeki toplam mikro kirleticileri azaltmada linyit kok tozu enjeksiyonu yöntemi işletmede uygulanmaktadır.

\subsection{EAO cüruflarının geri dönüşümü}

İşletmede açığa çıkan cüruf miktarı yıllık 250.000 t'dur. Oluşan cürufun küçük bir kısmı (tahmini \%5) geri dönüşüm tesislerine verilmekte, geri kalanı ise hiçbir işlem görmeden açık sahalarda stokta bekletilmektedir. Depolama alanı, toprak ve yeraltı sularına sızıntıyı önlemek amacıyla beton ile kaplanmıştır. Tesisin katı atık bertaraf sistemi bulunmamaktadır.

\subsection{EAO tozlarının geri dönüşümü}

Tesiste EAO tozlarının geri dönüşümünü sağlayacak bir sistem bulunmamakla beraber, bunların geri dönüşümünü yapabilecek büyük veya küçük ölçekli firmalarla iletişime geçilerek satışı yapılmaktadır.

BREF dokümanında yer alan, prosese bağlı MET'in işletmede uygulanma durumu Tablo 3'te özetlenmiştir. Prosese bağlı MET'in işletmede eksiksiz uygulandığ görülmektedir.

Tablo 3. BREF'te belirtilen prosese bağlı MET ile Baştuğ Metalurji'deki uygulamaların karşılaştırması

\begin{tabular}{llc}
\hline BREF & & Baştuğ Metalurji \\
\hline & $\begin{array}{l}\text { (Ultra) Yüksek güç uygulaması } \\
\text { (UHP) } \\
\text { Su soğutmalı yan duvarlar ve } \\
\text { çatılar } \\
\text { Oksi-yakıt yakıcılar ve oksijen } \\
\text { verme }\end{array}$ & Mevcut \\
EAO Proses & Aşağıdan dökme sistemi & Mevcut \\
Optimizasyonu & $\begin{array}{l}\text { Köpükü cüruf uygulaması } \\
\text { Pota veya ikincil metalurji }\end{array}$ & Mevcut \\
Hurda Ön Isıtma & Otomasyon & Mevcut \\
Kapalı Devre Su Soğutma Sistemleri & Mevcut \\
\hline
\end{tabular}

Boru sonu mevcut en iyi tekniklerin işletmedeki uygulanma durumu Tablo 4'te özetlenmiştir. EAO cüruflarının küçük bir kısmı geri dönüşüm firmalarına satılmakta, kalan kısmı ise atıl şekilde bekletilmektedir. EAO tozları baca tozu olarak firmalara satılmakta ve böylece geri dönüşüme katkı sağlanmaktadır.
Tablo 4. BREF'te belirtilen boru sonu MET ile Baştuğ Metalurji'deki uygulamaların karşılaştırması

\begin{tabular}{ll}
\hline BREF & Baştuğ Metalurji \\
\hline $\begin{array}{l}\text { İleri düzey emisyon toplama } \\
\text { Etkin sonradan yakma ve ileri düzey atık } \\
\text { gaz arıtımı }\end{array}$ & Yapılmakta \\
$\begin{array}{l}\text { Atık gaz arıtımında linyit kok tozu } \\
\text { enjeksiyonu }\end{array}$ & Yapılmakta \\
EAO cüruflarının geri dönüşümü & Yapılmamakta (\%5'i satılıyor) \\
EAO tozlarının geri dönüşümü & Yapılmamakta (Satılıyor) \\
\hline
\end{tabular}

\section{Sonuçlar}

$\mathrm{Bu}$ çalışma kapsamında demir-çelik tesislerinde oluşan katı atıklar ve geri dönüşüm teknikleri detaylı olarak incelenmiş, BREF dokümanındaki öneriler ile karşılaştırılmıştır. Ağır metal sanayi sektörü olan demir-çelik sektörü ton başına $400 \mathrm{~kg}$ aşan atık meydana getirmektedir. Böylesine atık oluşumunun kaçınılmaz olduğu durumlarda geri dönüşüm, tekrar kazanım ve ikincil hammadde elde etmek için atığın birtakım işlemler ile geri kazanılması veya enerji kaynağı olarak kullanılması gereklidir.

Demir-çelik tesislerinde oluşan katı atıklar; yüksek firın tozları ve çamurları, sinter ünitesi tozları, çelikhane toz ve çamurları, pota metalürji tesisleri tozları, yağlı tufaller, haddehane tufalleri, ark ocağı tozları ve cüruftur. Bu atıkların büyük bir çoğunluğunu cüruf oluşturmaktadır. Oluşan cürufu değerlendirerek geri dönüşümünü sağlamanın asıl amacı; cüruf içerisindeki alüminyumu yüksek metali geri kazanarak oluşan ikincil cürufu ise çevre açısından etkisiz bir forma dönüştürerek bu atığı ekonomik bir değere dönüştürmektir.

Demir-çelik tesislerinde atık olarak meydana gelen baca tozları, çamurları ve tozlaştırma tozları yüksek metal içeriğinden dolayı hammadde değeri yüksek bir atıktır. Ancak içeriğinde yüksek miktarda kurşun, çinko ve diğer bazı ağır metalleri bulundurması ve tanecik boyutunun değişken olmasından dolayı tesiste geri dönüşümünü sağlamak oldukça zordur. Bu atıkların geri dönüşümünü sağlamak için yapılan teorik hesaplar ve yöntemler mevcut olmakla birlikte yeterli değildir.

Demir-çelik üretimi sonucu oluşan kütüklerin şekil alması için haddeleme işlemi sırasında yüksek sıcaklıktan dolayı oluşan ince demir oksit tabakası tufal olarak nitelendirilmektedir. Tesislerde atık olarak sınıflandırılan tufal aslında bir yan ürün olarak işlem görmektedir. İçerdiği yüksek demir miktarı ve zararlı bileşen içermediğinden dolayı entegre demir-çelik tesislerinin sinter ünitelerinde kullanılarak geri dönüşümü sağlanmaktadır.

$\mathrm{Bu}$ çalışma kapsamında incelenen Baştuğ Metalürji demir-çelik tesisinin çelikhane ünitesinin MET'e uyum durumu tespit edilerek mevcut veriler üzerinden değerlendirmeler yapılmıştır. Baştuğ Metalürji'de "(Ultra) yüksek güç uygulaması-(UHP), su soğutmalı yan duvar ve çatılar, oksi-yakıt yakıcılar ve oksijen verme, aşağıdan dökme sistemi (EBT), köpüklü cüruf uygulaması, ikincil metalürji ve otomasyon sistemi" başlıklarını kapsayan EAO optimizasyonu tekniklerinin tümü tesiste mevcuttur. Hurda ön 1sıtma tesiste kullanılmamaktadır. Bu da tesisin emisyon oranlarının artmasına sebep olmaktadır. Tesiste ark ocağı 
yatay su kolonunda kapalı su soğutma sistemi kullanılırken, tesisin geri kalan bölümlerinde açık su soğutma sistemi kullanılmaktadır. BREF'te kapsam dışı bırakılan radyoaktivite kontrolü, tesis girişindeki ana kantarda bulunan radyasyon seviye ölçer cihazlar ile yapılmaktadır.

Boru sonu teknikler kapsamında ise "ileri düzey emisyon toplama, etkin sonradan yakma, ileri düzey atık gaz arıtımı, atık gaz arıtımında linyit kok tozu enjeksiyonu, EAO tozlarının ve cüruflarının geri dönüşümü" teknikleri kullanılmaktadır. Tesiste oluşan EAO cüruflarının az bir miktarı geri dönüșüm tesislerine gönderilirken, büyük çoğunluğu tesiste açık sahalarda bekletilmektedir. İşletmede açığa çıkan ortalama yıllık 250.000 t EAO cürufu için bir geri dönüşüm veya geri kazanım çözümü bulunması hem çevresel hem de ekonomik açıdan çok faydalı olacaktır. Benzer bir çalışma Erengüç [22] tarafından İÇDAŞ A.Ş.'ye ait EAO ile üretim yapan demir-çelik tesisinde yapılmış ve bu tesiste de MET'in büyük oranda uygulandığı tespit edilmiş; EAO cüruf ve tozlarının geri dönüşümü içinse mevcut bir sistemin olmadığı, fakat EAO cürufları için doğal ve elektro magnetler aracılığ 1 ile hizmet verecek bir katı atık arıtma tesisinin 2007 yılında, EAO tozlarının geri dönüşümü için tesisin de 2008 sonunda faaliyete geçeceği belirtilmiştir. $\mathrm{Bu}$ tesislerden elde edilen tecrübeler uygun bir çözüm üretilmesinde katkı sağlayabilir.

Diğer boru sonu tekniklerin büyük çoğunluğu tesiste eksiksiz uygulanmaktadır. Türkiye'de bir ilk olarak kullanılan AC tip, teleskopik tipli, 170 ton/döküm kapasiteli elektrik ark ocağı diğer türlere göre enerji ve üretim avantaj1 sağlamaktadır. İşletme, MET kapsamında sahip olduğu alt yapıda birkaç eksiğin giderilmesi ile EKÖK direktifine tamamen uyum sağlamak adına büyük bir zorlukla karşılaşmayacaktır.

İşletmelerde inceleme yapma ve bilgi almadaki zorluklar ve buna bağlı olarak ülkemizde benzer çalışmaların çok sınırlı olduğu göz önüne alındığında; bu çalışmanın demirçelik endüstrisi için yürürlüğe konmuş olan EKÖK Yönetmeliği'nin uygulamadaki karşılığının değerlendirilmesi açısından literatüre önemli katkı sağlayacağı, bundan sonraki benzer çalışmalar için işletmelere örnek teşkil edeceği düşünülmektedir.

\section{Teşekkür}

İnceleme ve araştırma yapmak üzere işletmelerini bize açan, ihtiyacımız olan bilgi ve verileri bizimle paylaşarak bu çalışmanın gerçekleştirilmesinde büyük katkı sağlayan Baştuğ Metalurji A.Ş.’ye teşekkür ederiz.

\section{Çıkar çatışması}

Yazarlar çıkar çatışması olmadığını beyan etmektedir.

\section{Benzerlik oranı (iThenticate): $\% 13$}

\section{Kaynaklar}

[1] R. Robinson, Studies low temperature self reduction of by-products from integrated iron and steel making. $\mathrm{PhD}$ Thesis, Lulea University of Technology, Lulea, Sweden, 2008.
[2] DOĞAKA, Demir çelik sektör raporu. T.C. Doğu Akdeniz Kalkınma Ajansı, Antakya, Hatay, Türkiye, 2014.

[3] Sanayi ve Verimlilik Genel Müdürlüğü, Demir çelik sektör raporu. T.C. Sanayi ve Teknoloji Bakanlığı, Ankara, Türkiye, 2019.

[4] UNEP, Environmental aspects of iron and steel production - A technical review. United Nations Environmental Programme, Industry \& Environment Technical Review Series, 1986.

[5] G. Doğantepe, Hematit karakterli demir cevherinden ve yüksek firın baca tozundan sünger demir üretilebilirliğinin araştırılması. Yüksek Lisans Tezi, Karabük Üniversitesi, Karabük, Türkiye, 2013.

[6] D. Bakar, Demir ve çelik tesislerinin yüksek demir ve karbon içeren atıklarını değerlendirme teknolojileri ve Erdemir için önerilen yöntemin tanıtımı. 3. Demir Çelik Kongresi ve Sergisi, Ereğli, Zonguldak, 22-24 Eylül 2005.

[7] J. Philipp and R. Endell, How German steel industry is managing waste disposal. Steel Technology International, 275-279, 1996.

[8] R. Robinson, High temperature properties of byproduct pellets containing blast furnace flue dust. Thermochimica Acta, 432 (1), 112-123, 2005. https://doi.org/10.1016/j.tca.2005.04.015

[9] E. Erünsal ve S. Perçinel, Entegre demir çelik fabrikalarında oluşan katı atıkları değerlendirme teknolojilerindeki son gelişmeler. 1. Ulusal Demir Çelik Sempozyumu ve Sergisi, sayfa 987-994, Ereğli, Zonguldak, Türkiye, 3-5 Ekim 2001.

[10] S. Dietz, Zero Waste Initiatives a Boon for the Scrap Metal Industry. Thermo Fisher Scientific, 2014. https://www.thermofisher.com/blog/metals/zerowaste-initiatives-a-boon-for-the-scrap-metal-industry/, Accessed 04.07.2019.

[11] A. Yılmaz ve A. H. Yıldız, Cüruf atıklarının yol inşaatında kullanılması durumunda çevresel etkileri. Uluslararası Burdur Deprem ve Çevre Sempozyumu, sayfa 267-279, Burdur, Türkiye, 7-9 Mayıs 2015.

[12] N. Sözbir, M. Akçil ve H. Okuyucu, Alüminyum cürufundan alüminyum metali ve flaks eldesi. ISEM2014 $2^{\text {nd }}$ International Symposium on Environment and Mortality, sayfa 1108-1113, Adıyaman, Türkiye, 24-26 Ekim 2014.

[13] N. P. Nayak, Characterization and utilization of solid wastes generated from Bhilai Steel Plant. MSc Thesis, National Institute of Technology, Department of Mining Engineering, Rourkela, India, 2008.

[14] M. Boyrazlı, Demir cevheri içerisindeki safsızlıkların olumsuz etkilerinin giderilme yollarının araştırılması. Doktora Tezi, Yıldız Teknik Üniversitesi, İstanbul, Türkiye, 2008.

[15] M. Suk, S. Jo, S. Kim, K. Lee, and J. Park, X-Ray observation of phosphorus vaporization from steelmaking slag and suppression method of phosphorus reversion in liquid iron. Metallurgical and Materials Transactions B, 37B, 100-107, 2006. 
[16] İskenderun Katı Atık Bertaraf Tesisi ÇED Başvuru Dosyası, Payas, Dörtyol, Hatay, 2009.

[17] G. Önkibar, Entegre demir çelik tesisi tufalinden doğrudan redüklenme yöntemi ile ham demir üretimi. Yüksek Lisans Tezi, Sakarya Üniversitesi, Sakarya, Türkiye, 2006.

[18] Council Directive 96/61/EC, Concerning integrated pollution prevention and control. Official Journal of the European Communities, 1996.

[19] AB Konseyi, Entegre Kirlilik Önleme ve Kontrol (IPPC) Direktifi, Demir ve çelik üretiminde en iyi teknolojiler referans dokümanı. Demir Çelik Üreticileri Derneği, Ankara, Şubat 2007.
[20] Baştuğ Metalürji Resmi İnternet Sitesi, https://bastugmetalurji.com.tr/index.php, Accessed 30.04.2020.

[21] R. Remus, M. A. Aguado-Monsonet, S. Roudier, and L. D. Sancho, JRS Reference Report: Best Available Techniques (BAT) reference document for iron and steel production. European Commission, Joint Research Centre, Institute for Prospective Technological Studies, Seville, Spain, 2013.

[22] A. Erengüç, AB Entegre Kirlilik Önleme ve Kontrolü Direktifi (IPPC) için düzenleyici etki analizi ve bir uygulama; demir çelik endüstrisi. Yüksek Lisans Tezi, İstanbul Teknik Üniversitesi, İstanbul, 2007. 